\title{
ARTROSE DE JOELHOS E ESTILO DE VIDA
}

\author{
UNASPRESS
}


Manter uma alimentação saudável auxilia no controle do peso e, assim, ajuda a diminuir a dor nos joelhos. Portanto, tenha uma dieta rica em alimentos in natura, evite os industrializados e reduza o consumo de sal e de doces. ${ }^{3}$

\section{Faça exercícios}

regularmente, como

caminhada, hidroginástica ou fisioterapia. A atividade física também ajuda a fortalecer os músculos e a proteger os joelhos. ${ }^{4}$

${ }^{3}$ MESSINA, O. D.; WILMAN, M. V:; NEIRA, L. F. V. Nutrition, osteoarthritis and cartilage metabolism. Aging Clinical and Experimental Research, [S.I.], V. 31, n. 6, p. 807-813, jun. 2019.

${ }^{4}$ ALFIERI, F. M.; VATRI, S.; OLIVEIRA, N. C.;

Osteoartrite de joelho e estilo de vida: revisão da literatura. Lecturas Educación Física y Deportes Buenos aires, v. 20, n. 206, p. 1, jul. 2015. 
Repouse. Aprenda a lidar com situações de estresse. Cultive a espiritualidade e os bons relacionamentos. Faça o uso correto da medicação indicada pelo seu médico. Essas atitudes também são essenciais para amenizar os sintomas da doença. ${ }^{5}$

${ }^{5}$ DARLOW, B.; BROWN, M.; THOMPSON, B; HUDSON, B.; GRAINGER, R.; MCKINLAY, E.; ABBOTT J. H. Living with osteoarthritis is a balancing act: an exploration of patients' beliefs about knee pain. BMC Rheumatology, [S.I.], v. 2, n. 1, p. jun. 2018. 
Também é importante manter uma boa postura nas diversas situações da vida diária, principalmente na hora de dormir, de se levantar, de carregar sacolas ou de fazer atividades domésticas. ${ }^{6}$

${ }^{6}$ PLOTNIKOFF, R.; KARUNAMUNI, N.; LYTWAK, E.; PENFOLD, C.; SCHOPFLOCHER, D.; IMAYAMA I.; JOHNSON, S. T.; RAINE, K. Osteoarthritis prevalence and modifiable factors: a population study. BMC

Public Health, [S.I.], v. 15, n. 1, p. 1195, nov. 2015. 


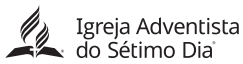

Divisão Sul-Americana da IASD

Presidente: Erton Köhler

Secretário: Edward Heidinger

Tesoureiro: Marlon Lopes

\section{Educação \\ \% Adventista}

Administração da Entidade Mantenedora (IAE)

Diretor-presidente: Maurício Lima

Diretor administrativo: Edson Medeiros

Diretor-secretário: Emmanuel Oliveira Guimarães

Diretor do departamento de educaçâo: Ivan Góes

\section{UN些SP}

Centro Universitário Adventista de São Paulo

Reitor: Martin Kuhn

Vice-reitores executivos / diretores de campus: Afonso Cardoso Ligório,

Antônio Marcos Alves, Douglas Jefferson Menslin

Vice-reitor Administrativo: Telson Bombassaro Vargas

Pró-reitor de graduação: Afonso Cardoso Ligório

Pró-reitor de pesquisa e desenvolvimento institucional: Allan Macedo de Novaes

Pró-reitor de educação a distância: Fabiano Leichsenring Silva

Pró-reitor de pós-graduação (lato sensu): Antônio Marcos Alves

Pró-reitor de desenvolvimento espiritual: Henrique Gonçalves

Diretores administrativos: Claudio Valdir Knoener, Flavio Knoner, Murilo Marques Bezerra

Diretor do Seminário adventista latino-americano de teologia : Reinaldo Wenceslau Siqueira

Diretor-geral de educação básica: Douglas Jefferson Menslin

Secretário-geral e procurador institucional : Marcelo Franca Alves

Diretora de recursos humanos: Karla Cristina de Freitas Souza

Diretor de produçoes artísticas: Tuiu Costa

Advogado-geral : Misael Lima Barreto Junior

Chefe de gabinete: Anna Cristina Pascual Ramos

\section{UNASPRESS}

Editora Universitária Adventista

Editor-chefe: Rodrigo Follis

Gerente de projetos: Bruno Sales Ferreira

Editor associado: Alysson Huf

Supervisor administrativo: Werter Gouveia

Supervisora de vendas e logística: Francileide Santos

Editores: Felipe Carmo, Gabriel Pilon Galvani, Kerilyn Oliveira, Luiza Simões, Peres Sales e Thamires Mattos

Revisora: Thaís Alencar

Designers gráficos: Felipe Rocha, Jônathas Sant'Ana e Kenny Zukowski 


\section{UN常SP}

Produção

Mestrado em Promoção da Saúde

\section{Autores}

Dra. Natália Cristina de Oliveira Vargas e Silva

Ma. Alessandra Rodrigues de Souto Lima

Dr. Fábio Marcon Alfieri

\section{Parecereristas ad hoc:}

Dr. Maurício Lamano

Centro Universitário Adventista de São Paulo (Unasp)

Dr. Elias Porto

Centro Universitário Adventista de São Paulo (Unasp)

\section{Conselho editorial e artístico:}

Dr. Martin Kuhn, Esp. Telson Vargas, Me. Antônio Marcos, Dr. Afonso Cardoso, Dr. Douglas Menslin, Dr. Rodrigo Follis, Dr. Allan Novaes, Dr. Reinaldo Siqueira, Dr. Fábio Alfieri, Dra. Gildene Lopes, Me. Edilson Valiante, Me. Diogo Cavalcante, Dr. Adolfo Suárez

\section{DOI}

http://doi.org/10.19141/artrosejoelhos

\section{UNASPRESS}

Editora Universitária Adventista

$\begin{aligned} \text { Coordenação editorial } & \text { Alysson Huf } \\ \text { Preparação } & \text { Jhoseyr Santos } \\ \text { Revisão } & \text { Ruben Holdorf } \\ \text { Projeto gráfico } & \text { Felipe Rocha } \\ \text { Imagens } & \text { Shutterstock }\end{aligned}$

